ORIGINAL ARTICLE

\title{
Randomised, controlled outcome study of active mobilisation compared with collar therapy for whiplash injury
}

M Schnabel, R Ferrari, T Vassiliou, G Kaluza

Emerg Med J 2004;21:306-310. doi: 10.1136/emj.2003.010165

See end of article for authors' affiliations .....................

Correspondence to: Dr R Ferrari, Room $2 \mathrm{G} 2$. 06, University of Alberta Hospital, Edmonton, Alberta, Canada, T6G 2B7; rferrari@shaw.ca

Accepted for publication 15 October 2003
Objectives: Standard therapy in Germany for acute whiplash injury has traditionally included a soft collar (cervical orthosis), an approach that is passive compared with early exercise and mobilisation. The purpose of this study is to examine the recovery in the first six weeks of groups of acute whiplash injury patients subjected to two different treatment approaches, the traditional approach of a collar compared with active, early mobilisation.

Methods: Between August 1997 and February 2000 a randomised clinical trial with a total of 200 patients was performed. A total of 97 were randomly assigned to a collar therapy group, and 103 to the exercise group, treated by a physiotherapist. Study participants recorded average pain and disability twice (baseline and six week follow up) during a one week period by diary, using numeric visual analogue (VAS) rating scales ranging from 0 to 10.

Results: The initial mean VAS pain intensity and VAS disability reported by the collar therapy group and the exercise group showed no statistical difference. The mean VAS pain rating reported by the collar therapy group after six weeks was 1.60 and mean VAS disability rating was 1.56 . The mean VAS pain intensity of the exercise group was 1.04 and mean VAS disability was 0.92 . These differences between the groups were both significant, as was the reduction in the prevalence of symptoms in the exercise therapy group compared with the collar group at six weeks.

Conclusions: Early exercise therapy is superior to the collar therapy in reducing pain intensity and disability for whiplash injury. l $\mathrm{n}$ this journal, a recent report of prescribing habits of emergency physicians indicated a comparatively high use of a soft collar (cervical orthosis) for acute whiplash injury. ${ }^{1}$ Recent reviews concerning the treatment of grade 1 and 2 whiplash associated disorders (WAD) (that is, excluding neurological injury or fractures-these being grade 3 and 4 WAD according to the Quebec task force grading scheme $^{2}$ ) have indicated that active therapy (exercise therapy) is probably superior to more traditional approaches entailing passive physiotherapy modalities (for example, ultrasound, laser, acupuncture, etc) or massage/chiropractic manipulation. ${ }^{3-6}$ In some countries, there is still a widespread tendency to rely on rest and collar use, such that it has long been held to be the standard effective therapy despite at least one small study (in Germany) indicating collar use may lead to an adverse outcome. ${ }^{7}$

Considering the Ferrari biopsychosocial model of whiplash, ${ }^{89}$ one of the elements of transition from acute to chronic pain may be the expectation that you have suffered a serious injury. This may lead injury victims and their therapists to believe that rest and allowing time to "heal the injury" is the best approach. A collar, rest, and medications seem intuitively to make sense as a beneficial treatment prescription. Controlled trials suggest that early exercise and mobilisation are, however, more effective, ${ }^{3-6}$ and recovery from acute whiplash injury is much faster and chronic pain uncommon or rare in countries such as Germany, ${ }^{7}$ Lithuania, $^{10}{ }^{11}$ and Greece ${ }^{12}{ }^{13}$ where little or no therapy seems to be required for this favourable outcome. It is thus important to conduct studies that put to the test the more traditional and possibly inappropriate therapeutic approaches to the management of whiplash injury. The purpose of this study is to evaluate the effectiveness of the traditional approach of collar use for at least one week compared with exercise therapy, to verify the findings of the single German population based study of collar use to date, and to do so in a larger sample size. ${ }^{7}$

\section{METHODS}

\section{Subjects}

In the period August 1997 to August 2000 consecutive patients who presented to the trauma department at the Philipps University of Marburg, Germany after a motor vehicle collision were evaluated for eligibility for recruitment into our study. To be included in our study, the subjects had to have at least one of pain, stiffness, or numbness along the spine, head, or limbs, presenting to our trauma department within 48 hours of having been an occupant in a motor vehicle involved in a collision, and be at least 18 years old (for consent). Patients were excluded if they suffered injuries consistent with grade 3 or 4 WAD, loss of consciousness, fractures of any body part, or they were too young to give consent, refused to give consent, or were pregnant. The first 200 subjects who met these criteria and gave consent were recruited into study and all agreed to participate.

Subjects were randomised to one of two treatment protocols by selecting a letter A or B, which then assigned them to a group. Group A had used a collar for one week, being advised to wear it "day and night". They were given no advice with regard to what pillow type they used or posture advice should they remove the collar. We later asked these collar users to self report on how many days of the one week they actually wore the collar and also how many hours per

Abbreviations: VAS, visual analogue scale; WAD, whiplash associated disorder 
day on average. It was our goal in this study to consider a "worst case" scenario for collar use, and not to provide any advice that might mitigate adverse effects of the collar use, such as exercise or posture advice. This increased the likelihood of avoiding cross contamination of the two treatment groups. Group B subjects received instruction with a physiotherapist on exercises for mobilisation of affected body regions. Both groups were prescribed diclofenac tablets ( $50 \mathrm{mg}$ three times daily), and were asked to refrain from other therapies (though no formal recording of use of "external" therapies was made). The exercise therapy group received anywhere from two to five visits with a physiotherapist in the first week depending on their needs and sites of injuries. This was an unblinded, concealed allocation randomised controlled trial.

\section{Sample size calculation}

Setting $\alpha$ at 0.05 , and $\beta$ at 0.10 , the sample size required to show a $30 \%$ benefit of one therapy over another is 140 . Assuming a drop out rate of at least $30 \%$, we aimed for recruitment of 200 subjects.

\section{Instruments}

Initial evaluation as well as follow up assessments six weeks after recruitment included structured interviews, a physical examination, and the pain diary. During the interview we recorded age, sex, collision type, occupant seating, seat belt use, compensation status. A visual analogue scale (VAS) rating of average total pain and degree of perceived disability for their normal activities were also used. Study participants recorded average pain and disability twice (baseline and six week follow up) during a one week period by diary, using numeric VAS rating scales ranging from 0 to 10 . We collected data about the number of days of use of diclofenac in the first week. We also measured claim for compensation status. (In Germany, within one week of the collision, those who perceive they have been injured at the fault of another may make a claim for monetary compensation from the offending driver's insurance company and this may involve litigation.) Physical examination was not used as an outcome measure as we were primarily interested in patient's perception of recovery. The examination was conducted to ensure no patients had developed signs of neurological injury that may have been missed initially.

\section{Statistical analysis}

We used $\chi^{2}$ test for comparisons between groups of prevalence of various characteristics and symptoms, and calculated the differences in pain and disability using the Mann-Whitney U test of significance.

\section{RESULTS}

A total of 97 subjects were randomised to collar therapy and 103 to exercise therapy. (The small difference in group numbers arose from the method of randomisation, which has subjects select a card marked either A or B, giving them a 50\% chance of entering a particular group.) Table 1 shows the age and sex distribution, as well as collision type, seat belt use, position in vehicle. No statistical differences were seen between the two groups. A comparison of initial prevalence of symptoms is shown in table 2, and again no statistical differences between the two groups are seen, except that the collar therapy group had more limb pain. There are some differences in the baseline characteristics of the subjects, such as shoulder pain and limb paresthesiae and visual disturbances, but these were not statistically significant. Adjustments for these non-significant differences (calculations not shown) did not change the presence of absence of statistical differences in the measures of outcome between the two treatment groups. A comparison of the baseline characteristics between the subjects of the two groups in the follow up analysis and also between the subjects of the two groups lost to follow up showed no significant differences in the baseline characteristics. There were no statistical differences in radiological findings of degenerative change or neck range of motion at the outset of the study (data not shown).

By six weeks after injury, $36 \%$ of the collar therapy group had dropped out, and $15 \%$ of the exercise therapy group had dropped out. There was no statistically significant difference in initial parameters between those who were lost to follow up and those who remained in either treatment group. Table 3 shows the prevalence of symptoms in each group at six weeks. The exercise therapy group had significantly less neck pain, headache, and shoulder pain with trends for a lower prevalence of all other symptoms in the exercise group,

\begin{tabular}{|c|c|c|}
\hline & Group A collar therapy & Group B exercise therapy \\
\hline Mean age (y) & 28.3 (SD 8.94) & 30.1 (SD 10.3) \\
\hline Sex $M: F(\%)$ & $39: 61$ & $38: 62$ \\
\hline \multicolumn{3}{|l|}{ Collision type } \\
\hline Frontal & 30 & 29 \\
\hline Rear & 39 & 41 \\
\hline Lateral & 10 & 12 \\
\hline Roll over (single vehicle) & 10 & 8 \\
\hline Multiple impacts & 10 & 9 \\
\hline Unknown, data missing & 0 & 1 \\
\hline \multicolumn{3}{|l|}{ Position in vehicle } \\
\hline Driver & 81 & 82 \\
\hline Front passenger & 15 & 16 \\
\hline Rear passenger & 3 & 3 \\
\hline \multicolumn{3}{|l|}{ Seat belt use } \\
\hline Yes & 97 & 92 \\
\hline No & 2 & 5 \\
\hline Unknown, data missing & 1 & 3 \\
\hline \multicolumn{3}{|c|}{ Claim made for bodily injury compensation } \\
\hline Yes & 42 & 49.5 \\
\hline No & 58 & 49.5 \\
\hline Unknown, data missing & 0 & 1 \\
\hline
\end{tabular}

Data show as percentages unless otherwise stated. 
Table 2 Symptom prevalence of study group A (collar therapy, $n=97$ ) and group $B$ (exercise therapy, $n=103$ ) at the start of the study

\begin{tabular}{llll}
\hline Symptom & Group A (\%) & Group B (\%) & p Value \\
\hline Neck pain & 95.9 & 97.1 & 0.641 \\
Headache & 60.8 & 59.2 & 0.817 \\
Shoulder pain & 54.6 & 43.7 & 0.122 \\
Back pain & 18.6 & 15.6 & 0.570 \\
Limb pain & 8.2 & 0.9 & 0.013 \\
Limb paresthesiae & 12.4 & 7.8 & 0.278 \\
Visual disturbance & 15.5 & 20.4 & 0.365 \\
Tinnitus & 7.2 & 2.9 & 0.163 \\
Dizziness & 34.0 & 34.0 & 0.995 \\
\hline
\end{tabular}

though this did not reach statistical significance. The exercise therapy group also reported significantly less diclofenac use in the first week than did the collar therapy group. Finally, table 4 shows the recovery as measured by pain and disability scores, comparing these scores at the start of the study and at six weeks later, with the exercise therapy group showing significantly less pain and disability. The collar group reported that, on average, the collar was worn for five of the seven days and for an average of 17 hours per day.

\section{DISCUSSION}

A recent survey of the management of whiplash injuries presenting to accident and emergency departments in Wales showed that $23 \%-47 \%$ of physicians (depending on staff grade) prescribe a soft collar for acute whiplash ("soft tissue") injury. ${ }^{1}$ Our study confirms, however, that exercise therapy, compared with use of a collar (or potentially the divergent effects of these two treatment approaches), results in a significant difference in recovery. This is in keeping with a similar previous study. ${ }^{7}$ The Quebec task force recommendation for active therapy and avoidance of collars is thus also justified. ${ }^{2}$ Active therapy with posture advice and exercises is superior to passive modalities such as massage, chiropractic adjustments, ultrasound, laser, etc. ${ }^{3-6}$ Simply advising a patient to "act as usual" and not permit sick leave after the accident also changes outcome, regardless of other therapies used. ${ }^{14}$ While our study involved two to five visits with a physiotherapist for the active group, it may be that even just one visit could have had the same or greater effect.

There are a number of potential biases in this study. Firstly, there may be an effect of contact with a therapist, which may have had a beneficial effect on subjects in the exercise therapy group, an effect which would be absent in the standard therapy (collar) group. The collar use subjects, before they began collar use, had more limb pain than the exercise group. As stated in the results section, however, this was not a factor in outcome when controlled for in analysis. The two groups became similar in prevalence of limb pain at six weeks. Thus, collar use did not increase the risk of limb pain. We do not know, however, if time alone or diclofenac use in the collar group eventually led to less limb pain by six weeks, and cannot yet state that collar use has any benefit in this regard.

Different drop out rates between groups might be attributable to the difference in personal patient-therapist contact. Given that drop outs did not differ from those who remained in various initial measures, we assume that the generalisability of our results is not biased by selection effects. Subjects were recruited from a hospital setting. This group may differ from those who do not present to hospital. Yet, we have no reason to believe that collar therapy would be any more beneficial to a group of patients who choose, for whatever reason, not to attend a hospital after injury. It may be that collar use is less detrimental if the patients are given specific advice to mitigate against its harmful effects. We are aware, for example, that clinicians who prescribe a collar will often also advise the patient to limit the collar use to mainly during the day, to sleep with an orthopaedic pillow, to gradually reduce the use of the collar after a few days, and to follow neck advice for good posture and exercises. This may compensate for the otherwise adverse effects of prolonged collar use. Approaching the investigation in this study with this type of advice, however, would not allow us to determine whether collar use itself was harmful, helpful, or had no effect, because a mixed prescription with, for example, exercise would confound the outcomes. We can, however, definitely state that wearing the collar for on average five days in the first week and for up to 17 hours per day (which is what our subject group did) is harmful. Future studies can be done now to determine if other collar prescriptions show lesser adverse effect on outcome, or even show benefit.

Whether or not the differences in these two groups would remain in the long term is unclear. We do believe, however, that any therapy approach that reduces patient suffering sooner, and that avoids other harm, is beneficial, as it allows patients perhaps to return to their normal function and

\begin{tabular}{|c|c|c|c|}
\hline Symptom & Group A (\%) & Group B (\%) & p Value \\
\hline Neck pain & 45.2 & 28.4 & 0.025 \\
\hline Headache & 27.4 & 13.6 & 0.028 \\
\hline Shoulder pain & 33.9 & 15.9 & 0.008 \\
\hline Back pain & 11.3 & 5.7 & 0.194 \\
\hline Limb pain & 6.5 & 2.3 & 0.198 \\
\hline Limb paresthesia & 6.5 & 4.5 & 0.609 \\
\hline Visual disturbance & 8.1 & 3.4 & 0.211 \\
\hline Tinnitus & 4.8 & 1.1 & 0.166 \\
\hline Dizziness & 8.1 & 6.8 & 0.773 \\
\hline No symptoms & 43.5 & 64.8 & 0.010 \\
\hline
\end{tabular}


Table 4 Neck pain intensity (VAS) and self assessed disability of study group A (collar therapy) and group B (exercise therapy) at the start of the study and six weeks after injury

\begin{tabular}{|c|c|c|c|c|c|c|c|c|}
\hline & \multicolumn{4}{|l|}{ Start of study } & \multicolumn{4}{|l|}{ At six weeks } \\
\hline & Group & Mean VAS & SD & p Value & Group & Mean VAS & SD & $p$ Value \\
\hline Pain & $\begin{array}{l}\text { A (collar) } \\
\text { B (exercise) }\end{array}$ & $\begin{array}{l}4.76 \\
4.36\end{array}$ & $\begin{array}{l}2.15 \\
2.14\end{array}$ & 0.224 & $\begin{array}{l}\text { A (collar) } \\
\text { B (exercise) }\end{array}$ & $\begin{array}{l}1.60 \\
1.04\end{array}$ & $\begin{array}{l}2.15 \\
1.81\end{array}$ & 0.047 \\
\hline Disability & $\begin{array}{l}\text { A } \\
B\end{array}$ & $\begin{array}{l}4.77 \\
4.28\end{array}$ & $\begin{array}{l}1.97 \\
2.09\end{array}$ & 0.119 & $\begin{array}{l}A \\
B\end{array}$ & $\begin{array}{l}1.56 \\
0.92\end{array}$ & $\begin{array}{l}2.22 \\
1.70\end{array}$ & 0.042 \\
\hline
\end{tabular}

independence sooner. We did not use a validated method for assessing self perceived disability, as symptom prevalence and intensity were the main outcome measures. We did feel it important to obtain the subjects' own assessment of any interference in their function in lifestyle or work, and simply asking them to rate this allowed them to take into consideration any and all sources (symptoms) that may be producing this effect. It is important to consider that the presence or absence of symptoms alone may not correlate with function, so some measure of disability is helpful. As well, an absence of symptoms may occur because of a restriction in activity, and thus a measure of disability is helpful. Again, this was not the main purpose of our study, but the results reflect both a reduction in symptom prevalence and self perceived disability in the exercise therapy group over the initial six weeks. Future studies will incorporate a general measurement of quality of health or a neck pain disability instrument, or both.

An incidental, and interesting result of this study, however, is that among 200 initial subjects, 56\% report no symptoms at six weeks, the recovery being even higher (65\% no symptoms at six weeks) in the exercise therapy group. By comparison, Canadian figures with similarly selected subjects indicate that at least six months' recovery time is required to achieve similar results despite more intensive therapy. ${ }^{16}$ The subjects of our study in Germany receive very little therapy compared with the clinical experience of the North American author (RF), whereupon whiplash patients in some countries receive thousands of dollars of therapy with little apparent effect. Our study size is at least as great as a number of studies in other countries that show a much worse recovery. A study in Canada $^{16}$ and one in Switzerland, ${ }^{17}$ for example, recruited subjects with similar criteria as we did, and were dealing with grade 1 and 2 WAD. Yet, the recovery at six weeks in Canada or Switzerland is much lower than in our study. While there may be some differences in selection procedures and outcome definitions, we do not see why potential differences should create the same poor outcome in Canada and Switzerland, the studies between these two countries having as many differences (if these are relevant) than they do with our study. Indeed, other studies in Canada, ${ }^{15}$ Sweden, ${ }^{18}{ }^{19}$ the United States, ${ }^{20}$ the United Kingdom, ${ }^{21}{ }^{22}$ and Ireland ${ }^{23}$ reveal poor recovery. If study design and selection bias can change the apparent outcome from whiplash injury, why does it repeatedly show such a poor outcome in all these Western countries, even though various methodologies are used? One could consider cultural stoicism, but we have no evidence that Germans are any more stoical than, say, Swiss or Canadians. When one compares German health surveys both of the general population and for chronic disorders with other countries, the results appear similar, which argues against an under-reporting due to stoicism. ${ }^{24-26}$ As well, were stoicism an important factor in outcome in our study, both groups would have been expected to have similar outcomes.

It is not clear what the differences may be between countries with very rapid recovery from acute whiplash injury (for example, Lithuania, Germany, Greece), and much slower recovery (for example, Canada, United States, Switzerland), but it is clear that there are vast cultural differences in the epidemiology of chronic whiplash and that this cannot be and has not been explained away by methodological issues. The biopsychosocial model that evolves is the necessary bridge to understanding the immense gaps in the recovery among various countries. In the end, attempts to understand why an epidemic of chronic whiplash exists in some cultures may very well begin by understanding why it does not in others. At the same time, we need to understand why some countries have such better recovery using comparatively less therapy. Based on this study, collar use as a standard therapy is to be discouraged in favour of exercise therapy in Germany. As well, it continues to appear that there are widely divergent outcomes from acute whiplash injuries and further investigation is required to discover why such excellent short term outcomes are achieved in some countries with little or no therapy.

\section{Authors' affiliations}

M Schnabel, T Vassiliou, Department of Trauma, Philipps University of Marburg, Klinikum Lahnberge, Marburg, Germany

R Ferrari, Department of Medicine, University of Alberta Hospital, Edmonton, Alberta, Canada

G Kaluza, Department of Medical Psychology, Philipps University of Marburg

\section{REFERENCES}

1 Logan AJ, Holt MD. Management of whiplash injuries presenting to accident and emergency departments in Wales. Emerg Med J 2003;20:354-5.

2 Spitzer WO, Skovron ML, Salmi LR, et al. Scientific monograph of the Quebec task force on whiplash associated disorders: redefining "whiplash" and its management. Spine 1995;20(suppl 8):1-73S

3 Kjellman GV, Skargren El, Öberg BE. A critical analysis of randomised clinical trials on neck pain and treatment efficacy. A review of the literature. Scand J Rehab Med 1999;31:139-52.

4 Peeters GG, Verhagen AP, de Bie RA, et al. The efficacy of conservative treatment in patients with whiplash injury: a systematic review of clinical trials. Spine 2001;26:E64-73.

5 Weinhardt C, Heller KD. A systemic review of the value of physical therapy in whiplash neck injury. Z Orthop Ihre Grenzgeb 2002;140:499-502.

6 Ferrari R, Russell AS. The problem with neck pain. Baillieres Clin Rheumatol 2003; 17:57-70.

7 Bonk A, Ferrari R, Giebel GD, et al. A prospective randomized, controlled outcome study of two trials of therapy for whiplash injury. Journal of Musculoskeletal Pain 2000;8:123-32.

8 Ferrari R, Schrader H. The late whiplash syndrome. A biopsychosocial approach. J Neurol Neurosurg Psychiatry 2001;71:722-6.

9 Ferrari R. The prevention of chronic pain after whiplash. Emerg Med J 2002; 19:526-30.

10 Schrader H, Obelieniene D, Bovim G, et al. Natural evolution of late whiplash syndrome outside the medicolegal context. Lancet 1996;347:1207-11.

11 Obelieniene D, Schrader H, Bovim G, et al. Pain after whiplash-a prospective controlled inception cohort study. J Neurol Neurosurg Psychiatry 1999;66:279-83.

12 Partheni M, Miliaris G, Constantayannis C, et al. Whiplash injury. [Letter] J Rheumatol 1999;26:1206-7.

13 Partheni M, Constantoyannis C, Ferrari R, et al. A prospective cohort study of the outcome of acute whiplash injury in Greece. Clin Exp Rheumatol 2000;18:67-70.

14 Borchgrevink GE, Smevik O, Nordby A, et al. MR imaging and radiography of patients with cervical hyperextension-flexion injuries after car-accidents. Acta Radiol 1995;36:425-8. 
15 Cassidy JD, Carroll L, Cote P, et al. Effect of eliminating compensation for pain and suffering on the outcome of insurance claims for whiplash injury. N Engl J Med 2000;342:1179-86.

16 Brison RJ, Hartling L, Pickett W. A prospective study of acceleration-extension injuries following rear-end motor vehicle collisions. Journal of Musculoskeletal Pain 2000;8:97-113.

17 Radanov BP, Di Stefano G, Schnidrig A, et al. Role of psychosocial stress in recovery from common whiplash. Lancet 1991;338:712-15.

18 Hildingsson C, Toolanen G. Outcome after soff-tissue injury of the cervical spine. Acta Orthop Scand 1990;61:357-9.

19 Berglund A, Alfredsson L, Cassidy JD, et al. The association between exposure to a rear-end collision and future neck or shoulder pain: a cohort study. J Clin Epidemiol 2000;53:1089-94.

20 Gennis P, Miller L, Gallagher EJ, et al. The effect of soft cervical collars on persistent neck pain in patients with whiplash injury. Acad Emerg Med 1996;3:568-73.
21 Gargan MF, Bannister GC. The rate of recovery following whiplash injury. Eur Spine J 1994;3:162-4.

22 Mayou R, Bryant B. Outcome of 'whiplash' neck injury. Injury 1996:27:617-23.

23 McKinney LA. Early mobilisation and outcome in acute sprains of the neck. BMJ 1989;299:1006-8.

24 Bruhlmann P, Stucki G, Michel BA. Evaluation of a German version of the physical dimensions of the Health Assessment Questionnaire in patients with rheumatoid arthritis. J Rheumatol 1994;21:1245-9.

25 Zink A, Braun J, Listing J, et al. Disability and handicap in rheumatoid arthritis and ankylosing spondylitis - results from the German rheumatological database. German Collaborative Arthritis Centers. I Rheumatol 2000;27:613-22.

26 Chrubasik S, Junck H, Zappe HA, et al. A survey on pain complaints and health care utilization in a German population sample. Eur I Anaesthesiol 1998;15:397-408 